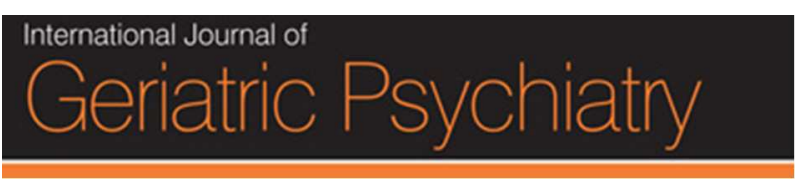

\title{
What becomes of people admitted to acute old age psychiatry wards? An exploration of factors affecting length of stay, delayed discharge and discharge destination.
}

\begin{tabular}{|r|l|}
\hline Journal: & International Journal of Geriatric Psychiatry \\
\hline Manuscript ID & GPS-16-0109.R1 \\
\hline Wiley - Manuscript type: & Research Article \\
\hline Complete List of Authors: & $\begin{array}{l}\text { Tucker, Sue; University of Manchester, Personal Social Services Research } \\
\text { Unit } \\
\text { Hargreaves, Claire; University of Manchester, Personal Social Services } \\
\text { Research Unit } \\
\text { Wilberforce, Mark; University of Manchester, Personal Social Services } \\
\text { Research Unit } \\
\text { Brand, Christian; University of Manchester, PSSRU; London School of } \\
\text { Hygiene and Tropical Medicine, Department of Health Services Research } \\
\text { and Policy } \\
\text { Challis, David; University of Manchester, Personal Social Services Research } \\
\text { Unit (PSSRU) }\end{array}$ \\
\hline Keywords: & $\begin{array}{l}\text { mental health services, length of stay, hospital discharge, delayed } \\
\text { discharge, psychogeriatric, older people }\end{array}$ \\
\hline
\end{tabular}

\section{SCHOLARONE ${ }^{\text {m }}$}

Manuscripts 


\section{Title:}

What becomes of people admitted to acute old age psychiatry wards? An exploration of factors affecting length of stay, delayed discharge and discharge destination.

\section{Running head:}

Acute old age psychiatry wards: length of stay and discharge

Keywords: mental health services; length of stay; hospital discharge; delayed discharge; psychogeriatric; older people

\section{Key points:}

- Profiling patients with prolonged admissions or delayed discharge might be expected to identify areas where changes in practice could improve care and save costs. However, recent accounts of people admitted to old age psychiatry inpatient wards are scarce.

- The mean length of stay (LoS) in this study was over nine weeks and more than 40 per cent of patients experienced a delayed discharge. Nevertheless, the vast majority of patients admitted from home returned there.

- Whilst a range of patient and service receipt variables were associated with patient outcomes, locality was also important.

- Local, multi-agency responses are needed to reduce LoS and delayed discharge. However, there is also an urgent need for a greater national focus on the scope, purpose and effectiveness of mental health inpatient care.

\section{Authors:}

Sue Tucker ${ }^{\mathrm{a}}$, Claire Hargreaves ${ }^{\mathrm{a}}$, Mark Wilberforce ${ }^{\mathrm{a}}$, Christian Brand ${ }^{\mathrm{a}, \mathrm{b}}$ and David Challis ${ }^{\mathrm{a}}$ 


\begin{abstract}
Affiliations:
a Personal Social Services Research Unit, University of Manchester

${ }^{\mathrm{b}}$ Department of Health Services Research and Policy, London School of Hygiene and Tropical Medicine
\end{abstract}

\title{
Corresponding author:
}

Sue Tucker

Research Fellow

PSSRU

University of Manchester

Crawford House

Booth Street East

Manchester

M13 9QS

Tel: 01612755938

Fax: 01612655790

E-mail: sue.tucker@manchester.ac.uk

\section{Sponsor / grant number:}

This article presents independent research commissioned by the National Institute for Health Research (NIHR) under its Programme Grants for Applied Research scheme (RP-PG-06061109). The views and opinions expressed by authors in this publication are those of the 


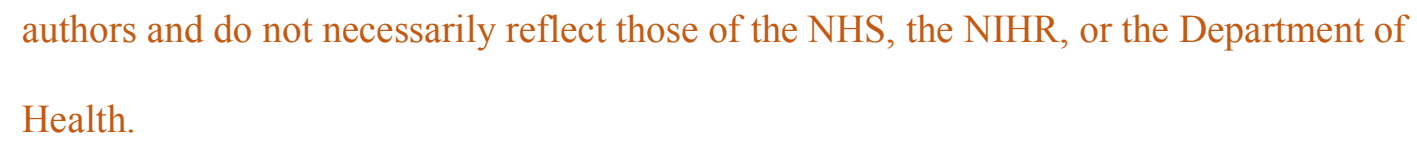

\section{Competing interests:}

None 


\section{Abstract}

Objectives: The study sought to identify the variables associated with increased length of stay (LoS) on old age psychiatry inpatient wards. It also explored the factors related to delayed discharge, and the likelihood of patients admitted from home returning there.

Methods: Data were collected on the sociodemographic, clinical and service receipt characteristics of a six-month series of admissions to seven wards in England in 2010/11. The cohort was followed for a 9-11 month period. The relationship between patients' status on admission and the specified outcome variables was explored.

Results: Information was collected on 216 admissions, of whom 165 were discharged in the study period. Mean LoS was 64 days. Female gender, higher dependency, greater challenging behaviour and locality predicted extended stay. Forty per cent of cases experienced delayed discharge. Better physical health, more cognitive impairment, receipt of social care and locality were associated with delayed discharge. The vast majority of patients admitted from home returned there. Younger patients and patients with less dependency, cognitive impairment and challenging behaviour had a higher likelihood of returning home. Patients receiving social care or admitted because of carer stress, a risk of self-neglect, accidental selfharm or abuse/exploitation were less likely to return home.

Conclusions: The study provides a useful starting point for identifying cases on which future efforts to improve inpatient outcomes might centre, and suggests local rather than national responses may be needed. It also highlights an urgent need for a national focus on the scope, purpose and effectiveness of acute inpatient care. 


\section{Introduction}

Health care systems internationally are being challenged to meet growing demand whilst simultaneously increasing productivity, constraining costs and improving outcomes (World Health Organization, 2007; McKinsey and Company, 2009). The case for allocating scarce resources in an efficient and effective manner is thus axiomatic (Williams and Robinson, 2012). Given the high proportion of healthcare expenditure accounted for by hospital inpatient beds, it is perhaps not surprising that their use is being particularly scrutinised (McDonagh et al., 2000; Bowen and Forte, 2012; Joynt and Jha, 2013). The issue is not whether hospital beds are needed - inpatient care is generally regarded as a fundamental component of both general and mental health services - but what should be provided for whom (Draper and Low, 2005; Appleby, 2012; Royal College of Physicians, 2012)?

In answering this question, many countries have sought to reduce unnecessary hospital admissions (Thompson and Poteliakhoff, 2011; Solberg, 2015). However, for patients who are admitted, there may also be opportunities to reduce length of stay (LoS) (NHS Institute for Innovation and Improvement, 2008; Royal College of Physicians, 2012). This includes facilitating the smooth and effective discharge of patients who no longer require acute hospital care, for delayed discharges are common and costly, prevent new admissions, and contribute to depression and dependency (Glasby and Lester, 2004; National Institute for Health and Care Excellence [NICE], 2015).

Over recent years, a number of policy initiatives have sought to address this issue in England. These include legislation permitting hospital trusts to charge local authorities (local government organisations) when general hospital beds are 'blocked' by people awaiting 
social care provision such as personal care or care home placement - a system known as 'reimbursement' (Community Care [Delayed Discharge] Act, 2003; Glasby et al., 2006), and the development of a range of rehabilitative intermediate care services to facilitate early discharge and increase the proportion of patients able to return home (Department of Health [DH], 2000; NHS Benchmarking et al., 2015).

To date, however, most of this activity has focused on older people in general hospital beds, and surprisingly little attention has been given to patients on specialist old age psychiatry (psychogeriatric) wards (Pinner et al., 2011). This is despite a median LoS of over 50 days (Health and Social Care Information Centre [HSCIC], 2013-14), high levels of delayed discharge (Barker and Bullock, 2005; Lewis and Glasby, 2006) and variable success in returning patients to their original environment (Moss et al.,1995; Draper and Low, 2005).

Against this background, profiling patients with prolonged admissions or delayed discharge might be expected to identify areas where changes in practice could improve care and save costs. Moreover, as a direct determinant of required bed numbers, understanding the factors that influence LoS is crucial to hospital planning (Kulinskaya et al., 2005). Official monitoring and routine data collection are limited (House of Commons Health Committee, 2002; Godden et al., 2008; NICE, 2015), however, and recent studies of old age psychiatry practice are sparse, with most published research dating from the 1980s and 1990s since when practice may have changed (e.g. Fulop et al., 1992; Domken et al., 1995; Paton et al., 2004; Shah, 2007). In light of this gap, this paper has three main aims: to examine the factors identified with (i) increased LoS on acute psychogeriatric wards; (ii) delayed discharge; and (iii) the likelihood that patients admitted from home will return there upon discharge - all issues of international relevance. 
Method

The data collection formed part of a larger study of the best mix of services to provide for older people with mental health problems in North-West England (Challis et al., 2014). Two wards were located in Site X, one for people with functional mental health problems and one for people with organic disorders; comparable facilities were provided in Site Y, which was managed by the same trust; and three wards were located in Site Z, each of which admitted a broad mix of patients with functional and organic disorders.

Data on the sociodemographic, functional and clinical characteristics of each patient were collected by nominated ward nursing staff shortly after admission using a bespoke data collection tool. This captured information on patients' age, gender, ethnicity, living situation, physical health, activities of daily living (ADLs), cognition, affect, behaviour and diagnosis, and contained a number of standardised measures (Mahoney and Barthel, 1965; Folstein et al., 1975; Yesavage et al., 1983; Zigmond and Snaith, 1983; Morris et al., 1994; Collin et al., 1998; Kroenke et al., 2003). It also collected information on the date and main reason for their admission (selected from a pre-determined list of 14 options), and their recent receipt of informal, specialist mental health and other community care. 
Further data was collected about each cohort member at discharge. First, as part of weekly multidisciplinary ward rounds, staff considered whether each individual was medically ready for discharge and, if so, recorded the date this applied from and the 'ideal' discharge destination (e.g. home, extra care housing $[\mathrm{ECH}]$ or a care home). Second, nominated nursing staff collected data on their actual discharge date and destination, as well as the reason for any delay in their leaving hospital.

Chi square, Mann-Whitney $\mathrm{U}$ and Kruskall-Wallis tests were used to explore the factors associated with three dependent variables: the number of days between admission and discharge ('LoS'); whether discharges occurred three or more days after patients were deemed ready for discharge ('delayed discharge'); and whether patients admitted from home subsequently returned there ('returned home'). In addition, a Cox proportional hazards model was used to explore whether inpatients' characteristics on admission were related to LoS. This analysis accounted for the censoring that occurs in time-to-event data, allowing patients who died in hospital or reached the end of the study period without being discharged $(10,11$ and 9 months after the data collection exercise began in sites $\mathrm{X}, \mathrm{Y}$ and $\mathrm{Z}$ respectively) to be included in the analysis. It also estimated the independent association of each variable with the dependent outcome after controlling for correlation with other variables (Smith et al., 2003).

Ethical approval for the study was granted by Cambridgeshire 3 Research Ethics Committee (reference number 10/H0306/51) and research governance procedures in each participating organisation were fulfilled. 


\section{Results}

\section{Inpatients' profile on admission}

Information was collected about 216 inpatient episodes (the unit of analysis): 67 in Site X, 53 in Site Y and 96 in Site Z. Of these, the vast majority (96\%) related to people with a single admission episode. A full description of the study sample is available elsewhere (Challis et al., 2014; Tucker et al., 2015). However, in summary, six-tenths of admissions were female, over four-fifths were under 85 (mean age 76.7 years) and more than three-quarters lived at home, with most of the remainder living in some form of institutional care. Approximately two-thirds were admitted directly from their usual residence, a fifth were transferred from a general hospital ward and a small number were admitted from another psychiatric hospital or respite placement.

More than a third of admissions had an organic mental health problem (most commonly dementia), whilst approaching half had an affective disorder (most commonly depression). The remainder had another functional mental health problem. Approximately a fifth were in poor physical health and a third needed help with ADLs. Just under a third had at least moderate cognitive impairment and the vast majority displayed at least moderate challenging behaviour.

Around two-fifths of the admissions who lived at home received eight or more hours per week informal care, but less than a third had a formal social care package. By way of contrast, over three-quarters of the full sample had received some specialist mental health 
input before admission. The most important reasons for the admission of people with dementia were the need for behavioural management and the risk of harm to others; the most important reasons for the admission of other cases were the risks of deliberate self-harm and self-neglect.

\section{Length of stay, delayed discharge and discharge destination}

Of the 216 admissions, 48 were still on an acute mental health ward at the end of follow-up, three had died in hospital and 165 had been discharged (Table 1). The discharges represented more than nine-tenths of admissions in Sites $\mathrm{X}$ and $\mathrm{Y}$, but only just over half in Site $\mathrm{Z}$ where baseline data collection started later. The mean $\operatorname{LoS}$ for the 159 cases for whom this information was available was 64 days (median 55 days), although the range and standard deviation were wide. Just under a third (29.6\%) of admissions were for 28 days or less.

Information on the presence/absence of a delay in discharge was provided for 130 cases. Only a minority of admissions (43.1\%) were discharged on the day they were deemed medically ready for discharge, whilst four-tenths had a delay of three or more days and approaching a tenth $(9.2 \%)$ were delayed more than two weeks. Information was rarely provided on the reason for short delays ( $<7$ days) but data were also missing for some substantial delays. Several reasons for delay were given, including problems finding a suitable care home, waiting for assessment by a care home, accessing funding for care home placement and waiting for a suitable care home vacancy. Difficulties arranging appropriate and timely community care packages reportedly accounted for the majority of delays in patients returning home. 
Information on prior and discharge residence was available for 145 admissions, of whom 19 were transferred to another mental health or general hospital ward, and one was discharged to respite care. Of the remaining 125, just under four-fifths returned to their former accommodation, including 82 of 99 cases admitted from home. Almost nine-tenths of discharges were to the setting ward staff deemed optimal.

\section{Table 1 about here}

\section{Factors associated with length of stay}

Bivariate analysis indicated LoS increased with patients' age and was greater for care home residents than for people who lived at home (Table 2). Higher levels of dependency, cognitive impairment and challenging behaviour were also associated with longer LoS. No significant relationship was found between LoS and gender, physical health, service receipt (including hospital site) or reason for admission. Nevertheless, people admitted because of carer stress or the risk of self-neglect, accidental self-harm or abuse/exploitation had a mean LoS approaching 20 days longer than people admitted because of the risk of deliberate selfharm or challenging behaviour. Patients admitted for assessment, review or treatment had a mean LoS approaching 10 weeks.

Table 2 about here

Four independent variables emerged as significant predictors of time to discharge in the Cox analysis (Table 3). The model estimated a six per cent decrease in the likelihood of discharge 
for every five point increase in Barthel score (with higher scores representing more dependency), whilst cases with moderate or high levels of challenging behaviour were 43 per cent less likely to be discharged than those with no/low levels. Hospital location was also a significant predictor - admissions in Site $\mathrm{Z}$ were 57 per cent less likely to be discharged than those in Sites $\mathrm{X}$ and $\mathrm{Y}$ - and weak evidence suggested females may experience a lower likelihood of discharge than males.

\section{Table 3 about here}

\section{Factors associated with delayed discharge}

Patients with greater cognitive impairment were more likely to experience delayed discharge than those with less impairment, as were those in fair-excellent as opposed to poor physical health (Table 4). However, no statistically significant relationship was found between delayed discharge and any other sociodemographic or clinical characteristic. Of the service receipt variables, patients who received formal social care before admission (at home or by virtue of care home/ECH residence) were more likely to experience a delay than people with no previous social care. Further, patients in Site $\mathrm{Z}$ were more likely to have a delayed discharge than patients in Sites $\mathrm{X}$ and $\mathrm{Y}$.

Table 4 about here

Factors associated with the likelihood of returning home 
Older patients and patients with high levels of ADL-dependency were significantly less likely to return home than younger or less dependent patients, as were patients with moderate or high (as opposed to low) levels of cognitive impairment or challenging behaviour (Table 5). People admitted because of a risk of carer stress or self-neglect, accidental self-harm or abuse/exploitation were also less likely to be discharged home than people admitted for other reasons, as were people who had a package of social care support before their admission.

\section{Table 5 about here}

\section{Discussion}

At a time in which healthcare funding is under unprecedented pressure (McKinsey and Company, 2009) and an old age psychiatry inpatient admission costs approximately $£ 350$ per day (DH, 2015), this exploratory research raises a raft of questions about the efficiency of bed utilisation. A selection of these are considered below.

Length of hospital stay

Although there have been extensive efforts to decrease LoS in general hospitals, this study suggests that many older people admitted to acute mental health wards continue to have prolonged stays. In comparing these findings with previous research, one must be mindful of the wider context, for recent decades have witnessed a rising number of older people with mental health problems and a declining number of hospital beds, leading to higher thresholds for hospital admission and longer hospital stays (Pinner et al., 2011; HSCIC, 2016). 
Nevertheless, by any measure an inpatient admission of over nine weeks is a considerable length of time.

In keeping with past research, the Cox analysis in this study found cognitive impairment to be a poor predictor of LoS (e.g. Moss et al., 1995; Draper and Luscombe, 1998). However, whilst previous work has reported inconsistent correlations with other patient variables, including age, gender, physical dependency, challenging behaviour and broad diagnosis (e.g. Domken et al., 1995; Junaid et al., 1996; Parks and Josef, 1997; Blank et al., 2005; Chung et al., 2010), this study suggests that patients with higher levels of dependency and/or challenging behaviour are particularly likely to have extended admissions. In theory, identifying such patients could facilitate changes in practice to reduce LoS e.g. the introduction of targeted interventions to address challenging behaviour. The provision of appropriate care is, however, complicated by the multiple and complex needs this client group presents, and despite a growing body of research in this field, (e.g. Opie and Rosewarne, 1999; Moniz-Cook et al., 2008; Brodaty and Arasaratnam, 2012), there is a paucity of evaluations in hospital settings (Draper and Low, 2005; Pinner et al., 2011). Furthermore, although clinical pathways defining staff responsibilities, timelines and patient outcomes have been widely used to improve quality, clinical and financial outcomes on medical and surgical wards, examples of their employment in mental health care are rare (Bultema et al., 1996; Draper and Low, 2005).

If this suggests an urgent need for more research on the direct care and treatment provided in mental health inpatient settings, future studies might also explore the difference between localities evident in this study, and the extent to which these can be attributed to variations in administrative procedures, service availability or clinical practice. The fact that patients on 
wards where (contrary to usual practice) older people with organic and functional problems were treated on the same ward, had the longest admission duration, is, for example, considered worthy of further investigation. It may also be timely to re-open discussion on the scope and purpose of acute inpatient care. The finding that patients primarily admitted for assessment, review or treatment (as opposed to problems too severe to be managed in the community), for instance, had a mean LoS approaching ten weeks makes one wonder if at least some of these cases could have been more appropriately managed in the community.

\section{Delayed discharge}

The finding that 40 per cent of admissions in this study had a delayed discharge suggests that achieving timely discharge from acute mental health wards remains a significant challenge. Although it is hard to define an 'acceptable level' of delay, it is unlikely that many people would find a wait of more than a fortnight acceptable.

Consistent with earlier work, patients with higher levels of cognitive impairment were particularly vulnerable to delayed discharge (Koffman et al., 1996). This is not to imply that patients' 'problems' per se were the issue, as witnessed by the finding that people in poor physical health were less likely than people in better health to experience delay. There was also little indication of poor communication with local authorities. Indeed, patients known to social care services before their admission were more likely to experience delay than those who were not. Rather the findings would appear to support wider evidence indicating that delays in discharge are primarily due to difficulties accessing appropriate services (Glasby et al., 2006; Baumann et al., 2007; Gaughan et al., 2015), and give some indication of the 
particular support that was lacking e.g. specialist services for people who present with cognitive and behavioural symptoms of dementia but are physically fit.

Such concerns would seem to call for a multiple agency response involving new ways of working across service boundaries, including those between community and inpatient mental health services. This might encompass the use of electronic records and/or knowledge sharing proformas as currently being tested in one mental health trust's adult care services (Rowley et al., 2014), and the introduction of common management arrangements, staff rotation, integrated training and (in some cases) co-location (Naylor and Bell, 2010). Further, the identified variation between sites again highlights the importance of understanding the local context text deleted here (Glasby et al., 2006; NICE, 2015). Indeed, whilst much of the reaction to the rising number of delayed discharges from general hospitals has been at a national level, it would seem there is an argument for a more local response here, particularly given the noted lack of appetite for an extension of the reimbursement policy to mental health services (Lewis and Glasby, 2006) and the absence of mental health workers in most intermediate care teams (NHS Benchmarking et al., 2015).

Ability to return home

In a culture that promotes community care for older people wherever possible (DH, 2001; Pavolini and Ranci, 2013), this study found that the vast majority of patients admitted from home were able to return there. Echoing research from the 1980s and 90s, however, patients with higher levels of dependency, cognitive impairment and challenging behaviour were less likely to return home than patients with lower levels (Domken et al., 1995). The importance of daily functioning concurs with the wider body of research on patients discharged from 
general hospital wards. For example, functional independence was a significant predictor of discharge destination in a large European study of older people admitted to acute medical settings (Campbell et al., 2005), and the key predictor of discharge setting in a study of a combined geriatric medicine/old age psychiatry unit in Scotland (Astell et al., 2008). Whilst few older people are likely to be admitted to an acute mental health bed solely because of their functional dependence, this might suggest that hospital staff should pay equal attention to addressing ADL as to behavioural and psychological needs. This is not to say that home will be the most appropriate discharge setting for all admissions, however. Indeed, the proportion of patients discharged to what staff, patients and carers consider the optimal setting may be a better measure for future studies to consider, with users' perspectives seemingly neglected in previous research.

\section{Methodological considerations}

This study represents the practice of the local health and social care system in three areas of North-West England. The extent to which the findings can be generalised to other areas is unclear, for, as shown, the results varied between localities (albeit the median LoS was very close to the national average). Furthermore, although the study period was felt to provide a representative picture of current practice, the relatively high proportion of patients who remained in hospital at the end of data collection reduced the sample size, and the high level of missing data for some potential variables of interest precluded their inclusion in the analysis. Future work would benefit from following a larger cohort of admissions over a longer period. 
This study asked multi-disciplinary staff attending hospital-based ward rounds to identify delayed discharges. However, it is possible that other staff groups (including communitybased practitioners) would have made different decisions. Moreover, it is not known whether the participating wards actively planned for discharge from admission (based on estimated discharge dates) or waited until later in people's hospital stays before, for example, referring to other agencies. Finally, in interpreting the findings, one should bear in mind that the studied outcomes will not have been independent of one another. Moreover, whilst the implicit assumption is that lengthy hospital stay is 'a bad thing', this may not always be true. Evidence is lacking on the potential trade-off between inpatient LoS and patient outcomes.

\section{Conclusions}

Given the lack of contemporary research on the LoS and discharge of acute mental health inpatients, the current study provides a useful starting point for identifying cases and issues on which future efforts to improve practice might profitably focus and highlights the importance of understanding the local context. Perhaps not surprisingly given the complex, multi-faceted nature of the questions it addresses, it also identifies a number of areas where future work is needed and may more generally be seen as a call for a greater focus on the scope, purpose and effectiveness of acute hospital care. Indeed, as a report by the Royal College of Psychiatrists states, given that mental health inpatient care focuses on some of the most vulnerable older people in our society, costs a large proportion of the mental health budget and employs the biggest number of staff, it is amazing that there has to date been so little focus on how it is best delivered (Pinner et al., 2011). 


\section{References}

Appleby J. 2012. Hospitals: what do they do and how much does it cost? BMJ 344, e1759.

Astell AJ, Clark SA, Hartley NT. 2008. Predictors of discharge destination for 234 patients admitted to a combined geriatric medicine/old age psychiatry unit. Int J Geriatr Psych 23(9): 903-908.

Barker A, Bullock R. 2005. Delayed discharge in older people's mental health beds. Old Age Psychiatrist Autumn: 9.

Baumann M, Evans S, Perkins M, et al. 2007. Organisation and features of hospital, intermediate care and social services in English sites with low rates of delayed discharge. Health Soc Care Community 15(4): 295-305.

Blank K, Hixon L, Gruman C, et al. 2005. Determinants of geropsychiatric inpatient length of stay. Psychiatric Q 76(2): 195-212.

Bowen T, Forte P. 2012. Idealised design and modelling of alternatives to hospital care. In Advanced Decision Making Methods Applied to Health Care, Tanfani E, Testi A. (eds). Springer: Milan; 33-50.

Brodaty H, Arasaratnam C. 2012. Meta-analysis of nonpharmacological interventions for neuropsychiatric symptoms of dementia. Am J Psych 169(9): 946-953. 
Bultema JK, Mailliard L, Getzfrid MK, et al. 1996. Geriatric patients with depression. Improving outcomes using a multidisciplinary clinical path model. J Nurs Adm 26(1): 31-38.

Campbell SE, Seymour DG, Primrose WR, et al. 2005. A multi-centre European study of factors affecting the discharge destination of older people admitted to hospital: Analysis of inhospital data from the ACME plus project. Age Ageing 34(5): 467-475.

Challis D, Tucker S, Wilberforce M, et al. 2014. National trends and local delivery in old age mental health services: towards an evidence base. A mixed-methodology study of the balance of care approach, community mental health teams and specialist mental health outreach to care homes. PGfAR vol 02: no. 04.

Chung W, Oh S-M, Suh T, et al. 2010. Determinants of length of stay for psychiatric inpatients: analysis of a national database covering the entire Korean elderly population. Health Policy 94(2): 120-128.

Collin C, Wade DT, Davies S, et al. 1988. The Barthel ADL Index: a reliability study. Int Disabil Stud 10(2): 61-63.

Department of Health. 2000. The NHS Plan: A Plan for Investment, A Plan for Reform. Department of Health: London.

Department of Health. 2001. National Service Framework for Older People. London: Department of Health: London. 
Department of Health. 2015. NHS reference costs 2014 to 2015.

https://www.gov.uk/government/publications/nhs-reference-costs-2014-to-2015 accessed 26 January 2016.

Domken M, Bothwell R, McKeith I. 1995. Discharge patterns from a psychogeriatric inpatient unit. Int J Geriatr Psych 10(1): 41-46.

Draper B, Low LF. 2005. What is the effectiveness of acute hospital treatment of older people with mental disorders? Int Psychogeriatr 17(4): 539-555.

Draper B, Luscombe G. 1998. Quantification of factors contributing to length of stay in an acute psychogeriatric ward. Int J Geriatr Psych 13(1): 1-7.

Field A. 2005. Discovering statistics using SPSS. SAGE: London.

Folstein MF, Folstein SE, McHugh PR. 1975. "Mini-mental state". A practical method for grading the cognitive state of patients for the clinician. J Psychiatr Res 12(3):189-198.

Fulop N, Koffman J, Hudson M. 1992. Challenging bed behaviours: The use of acute psychiatric beds in an inner-London district health authority. J Ment Health 1(4): 335-341.

Gaughan J, Gravelle H, Siciliani L. 2015. Testing the Bed-Blocking Hypothesis: Does Nursing and Care Home Supply Reduce Delayed Hospital Discharges? Health Econ 24(Suppl 1): $32-44$. 
Glasby J, Lester H. 2004. Delayed hospital discharge and mental health: The policy implications of recent research. Soc Policy Admin 38(7): 744-757.

Glasby J, Littlechild R, Pryce K. 2006. All dressed up but nowhere to go? Delayed hospital discharges and older people. J Health Serv Res Policy 11(1): 52-58.

Godden S, McCoy D, Pollock AM. 2008. Using SitReps performance data to monitor the delayed discharge process. Health Serv Manage Res 21(3): 155-160.

Health and Social Care Information Centre. 2013-14. Hospital Episode Statistics, Admitted Patient Care, England - 2013-14 [NS]. http://www.hscic.gov.uk/catalogue/PUB16719 accessed 04 March 2016.

Health and Social Care Information Centre. 2016. http://www.hscic.gov.uk/home accessed 26 January 2016.

House of Commons Health Committee. 2002. Delayed Discharges (Third Report). TSO: London.

Joynt KE, Jha A. 2013. A path forward on Medicare readmissions. $N$ Engl J Med 368(13): 1175-1177.

Junaid O, Page K, Blagden K, et al. 1996. Destination and dependency of psychogeriatric inpatients at discharge from Nottingham hospitals following the 1990 NHS and Community Care Act. Int J Geriatr Psychiatry 11(9): 787-793. 
Koffman J, Fulop NJ, Pashley D, et al. 1996. No way out: The delayed discharge of elderly mentally ill acute and assessment patients in North and South Thames Regions. Age Ageing 25(4): 268-272.

Kroenke K, Spitzer RL, Williams J. 2003. The Patient Health Questionnaire-2: Validity of a Two-Item Depression Screener. Med Care 41(11):1284-1292.

Kulinskaya E, Kornbrot D, Gao H. 2005. Length of stay as a performance indicator: robust statistical methodology. IMA J Manag Math 16(4), 369-381.

Lewis R, Glasby J. 2006. Delayed discharge from mental health hospitals: results of an English postal survey. Health Soc Care Community 14(3): 225-230.

Mahoney FI, Barthel DW. 1965. Functional evaluation: the Barthel Index: a simple index of independence useful in scoring improvement in the rehabilitation of the chronically ill. Rehabil 4:61-65.

McDonagh MS, Smith DH, Goddard M. 2000. Measuring appropriate use of acute beds: A systematic review of methods and results. Health Policy 53(3):157-184.

McKinsey and Company. 2009. Achieving world class productivity in the NHS 2009-102013-14: Detailing the size of the opportunity. http://webarchive.nationalarchives.gov.uk/20130107105354/http://www.dh.gov.uk/prod_cons um_dh/groups/dh_digitalassets/documents/digitalasset/dh_116521.pdf accessed 26 January 2016. 
Moniz-Cook E, Elston C, Gardiner E, et al. 2008. Can training community mental health nurses to support family carers reduce behavioural problems in dementia? An exploratory pragmatic randomised controlled trial. Int J Geriatr Psychiatry 23(2): 185-191.

Morris JN, Fries BE, Mehr DR, et al. 1994. MDS Cognitive Performance Scale. J Gerontol 49(4):M174-182.

Moss F, Wilson B, Harrigan S, et al. 1995. Psychiatric diagnoses, outcomes and lengths of stay of patients admitted to an acute psychogeriatric unit. Int $J$ Geriatr Psychiatry 10(10): 849-854.

National Institute for Health and Care Excellence. 2015. Transition between inpatient hospital 8 settings and community or care home settings for adults with social care needs. Draft for consultation June 2015. http://www.nice.org.uk/guidance/NG27/documents/transitionbetween-inpatient-hospital-settings-and-community-or-care-home-settings-for-adults-withsocial-care-needs-full-guideline2 accessed 26 January 2016.

Naylor C, Bell A. 2010. Mental Health and the Productivity Challenge. Improving quality and value for money. The King's Fund: London.

NHS Benchmarking et al.. 2015. National Audit of Intermediate Care Summary Report 2015. Assessing progress in services for older people aimed at maximising independence and reducing use of hospitals. NHS Benchmarking Network: Manchester. 
NHS Institute for Innovation and Improvement. 2008. Length of stay - Reducing length of stay. Available

from:

http://www.institute.nhs.uk/quality_and_service_improvement tools/quality and service im provement tools/length_of_stay.html. Accessed January 2016.

Opie J, Rosewarne R, O’Connor DW. 1999. The efficacy of psychosocial approaches to behaviour disorders in dementia: a systematic literature review. Aust N Z J Psychiatry 33(6): 789-799.

Parks ED, Josef N. 1997. A retrospective study of determinants of length of stay in a geropsychiatric state hospital. Psychiatr $Q$ 68(2): 91-99.

Paton JM, Fahy MA, Livingston GA. 2004. Delayed discharge - a solvable problem? The place of intermediate care in mental health care of older people. Aging Ment Health, 8(1): 3439.

Pavolini E, Ranci C. 2013. Reforms in Long-Term Care Policies in Europe: An Introduction. In Reforms in Long-Term Care Policies in Europe: Investigating Institutional Change and Social Impacts, Ranci C, Pavolini E. (eds). Springer Science + Business Media: Milan; 3-22.

Pinner G, Hiller J, Branton T, et al. 2011. In-patient care for older people within mental health services. Royal College of Psychiatry: London.

Rowley E, Wright N, Waring J, et al. 2014. Protocol for an exploration of knowledge sharing for improved discharge from a mental health ward. BMJ Open, 4:e005176. 
Royal College of Physicians. 2012. Hospitals on the Edge? The time for action. Royal College of Physicians: London.

Shah A. 2007. The impact of the Community Care (Delayed Discharge) Act 2003 on the length of stay and bed occupancy in Old Age Psychiatry Units in England. Int $J$ Geriatr Psychiatry 22(11), 1164-1165.

Smith T, Smith B, Ryan M. 2003. Survival Analysis Using Cox Proportional Hazards Modelling for Single and Multiple Event Time Data. Paper 254-28. http://www2.sas.com/proceedings/sugi28/254-28.pdf accessed 26 January 2016.

Solberg LI. 2015. Preventable hospital admissions: are they? Fam Pract 32(3), 245-246.

Thompson J, Poteliakhoff E. 2011. Data briefing: Emergency bed use. What the numbers tell us. http://www.kingsfund.org.uk/publications/data-briefing-emergency-bed-use accessed 26 January 2016.

Tucker S, Brand C, Wilberforce M, et al. 2015. Identifying alternatives to old age psychiatry inpatient admission: an application of the balance of care approach to health and social care planning. BMC Health Serv Res 15:267. doi: 10.1186/s12913-015-0913-1.

Williams I, Robinson S. 2012. Decision making and priority setting. In Commissioning for health and well-being, Glasby J (ed). Policy Press: Bristol; 63-84. 
World Health Organization. 2007. Everybody's business -- strengthening health systems to improve health outcomes: WHO's framework for action. World Health Organization: Geneva.

Yesavage JA, Brink TL, Rose TL, et al. 1983. Development and validation of a geriatric depression screening scale: A preliminary report. J Psychiatr Res 17(1):37-49.

Zigmond AS, Snaith RP. 1983. The Hospital Anxiety and Depression Scale. Acta Psychiatr Scand 67(6):361-370. 
Table 1. Length of stay, delayed discharge and discharge destination*

\begin{tabular}{|c|c|c|c|}
\hline Variable & $\mathrm{n}$ & $\%$ & Mean $\left(\mathrm{SD}^{* *}\right)$ \\
\hline \multicolumn{4}{|c|}{ Completed care episodes (total number of admissions) } \\
\hline Site X & $63(67)$ & 38.2 & \\
\hline Site Y & $51(53)$ & 30.9 & \\
\hline Site Z & $51(96)$ & 30.9 & \\
\hline Length of inpatient stay & 159 & & 63.6 days $(51.5)$ \\
\hline \multicolumn{4}{|l|}{ Delayed discharge } \\
\hline$<3$ days & 78 & 60.0 & \\
\hline$\geq 3$ days & 52 & 40.0 & \\
\hline \multicolumn{4}{|c|}{ Ability to return home (admissions from home only) } \\
\hline Able to return home & 82 & 82.8 & \\
\hline Unable to return home & 17 & 17.2 & \\
\hline \multicolumn{4}{|c|}{ Ability to return to previous setting } \\
\hline Returned to previous setting & 92 & 78.0 & \\
\hline Changed setting & 26 & 22.0 & \\
\hline
\end{tabular}


Table 2. Factors associated with length of stay (sample with completed hospital episode only)

\begin{tabular}{|c|c|c|c|c|c|}
\hline Independent variable & $\mathrm{n}$ & $\begin{array}{l}\text { Mean length of stay } \\
\text { (SD*) }\end{array}$ & $\begin{array}{c}\text { Test } \\
\text { statistic }\end{array}$ & $\mathrm{df}$ & $\mathrm{p}$-value \\
\hline \multicolumn{6}{|l|}{ Gender } \\
\hline Male & 59 & $69.6(47.4)$ & \multirow{2}{*}{$2441.0^{\mathrm{a}}$} & \multirow{2}{*}{1} & \multirow{2}{*}{.085} \\
\hline Female & 99 & $59.7(53.9)$ & & & \\
\hline Age & 156 & & $.180^{\mathrm{b}}$ & & .025 \\
\hline \multicolumn{6}{|l|}{ Living situation prior to admission } \\
\hline Home alone no informal care & 37 & $66.9(49.9)$ & \multirow{4}{*}{$8.5^{\mathrm{c}}$} & \multirow{4}{*}{3} & \multirow{4}{*}{.036} \\
\hline Home with informal care & 84 & $56.1(43.6)$ & & & \\
\hline Care home and ECH & 30 & $87.7(68.5)$ & & & \\
\hline Other & 6 & $33.3(28.2)$ & & & \\
\hline \multicolumn{6}{|l|}{ Physical health status } \\
\hline Poor & 35 & $54.9(47.1)$ & \multirow{2}{*}{$1803.0^{\mathrm{a}}$} & \multirow{2}{*}{1} & \multirow{2}{*}{.228} \\
\hline Fair to excellent & 119 & $65.5(53.5)$ & & & \\
\hline Daily functioning (Barthel score) & 159 & & & & $.018^{\mathrm{b}}$ \\
\hline \multicolumn{6}{|l|}{ Cognitive impairment } \\
\hline Low & 114 & $55.9(43.3)$ & \multirow{3}{*}{$6.9^{\mathrm{c}}$} & \multirow{3}{*}{2} & \multirow{3}{*}{.031} \\
\hline Moderate & 17 & $88.3(56.8)$ & & & \\
\hline High & 28 & $79.7(69.6)$ & & & \\
\hline \multicolumn{6}{|l|}{ Behaviour problems } \\
\hline No/low challenging behaviour & 21 & $39.5(30.8)$ & \multirow{2}{*}{$987.5^{\mathrm{a}}$} & \multirow{2}{*}{1} & \multirow{2}{*}{.019} \\
\hline Moderate/high challenging behaviour & 138 & $67.2(53.0)$ & & & \\
\hline \multicolumn{6}{|l|}{ Mental health support pre-admission } \\
\hline No formal mental health support & 36 & $66.8(57.2)$ & \multirow{2}{*}{$2110.0^{\mathrm{a}}$} & \multirow{2}{*}{1} & \multirow{2}{*}{.833} \\
\hline Formal mental health support & 120 & $63.7(50.0)$ & & & \\
\hline \multicolumn{6}{|l|}{ Social care support pre-admission } \\
\hline No formal social care support & 88 & $57.1(42.4)$ & \multirow{2}{*}{$2655.5^{\mathrm{a}}$} & \multirow{2}{*}{1} & \multirow{2}{*}{.178} \\
\hline Formal social care support & 69 & $72.7(60.7)$ & & & \\
\hline \multicolumn{6}{|l|}{ Reason for hospital admission } \\
\hline $\begin{array}{l}\text { Risk of self-neglect / accidental self-harm } \\
\text { / abuse or exploitation, carer stress }\end{array}$ & 36 & $74.7(49.3)$ & & & \\
\hline $\begin{array}{l}\text { Challenging behaviour, risk of deliberate } \\
\text { self- harm, other care breakdown }\end{array}$ & 83 & $56.4(48.2)$ & $5.2^{\mathrm{c}}$ & 2 & .075 \\
\hline Assessment, review or treatment & 35 & $69.7(59.9)$ & & & \\
\hline Hospital site & & & & & \\
\hline Site X & 62 & $62.3(50.8)$ & & & \\
\hline Site Y & 48 & $76.4(64.9)$ & $1.7^{\mathrm{c}}$ & 2 & .428 \\
\hline Site $\mathrm{Z}$ & 49 & $52.5(32.0)$ & & & \\
\hline
\end{tabular}

*Standard deviation; ${ }^{\mathrm{a}}$ Mann-Whitney U test; ${ }^{\mathrm{b}}$ Pearson Correlation; ${ }^{\mathrm{c}}$ Kruskal-Wallis test 
Table 3. Predictors of time to discharge

\begin{tabular}{|c|c|c|c|c|}
\hline Independent variable & $\beta$ & Standard error & Hazard ratio & p-value \\
\hline \multicolumn{5}{|l|}{ Gender } \\
\hline \multicolumn{5}{|l|}{ Male (reference) } \\
\hline Female & -0.330 & 0.177 & 0.719 & 0.063 \\
\hline Daily functioning (Barthel score*) & -0.013 & 0.004 & 0.988 & 0.006 \\
\hline \multicolumn{5}{|l|}{ Behaviour problems } \\
\hline \multicolumn{5}{|l|}{$\begin{array}{l}\text { No/low challenging behaviour } \\
\text { (reference) }\end{array}$} \\
\hline Moderate to high challenging behaviour & -0.560 & 0.242 & 0.571 & 0.034 \\
\hline \multicolumn{5}{|l|}{ Hospital location } \\
\hline \multicolumn{5}{|l|}{ Other (reference) } \\
\hline Site $\mathrm{Z}$ & -0.854 & 0.190 & 0.426 & $<.001$ \\
\hline
\end{tabular}

2

5

6

7

8

9

10

11

12

13

14

15

16

17

18

19

20

21

22

23

24

25

26

27

28

29

30

31

32

33

34

35

36

37

38

39

40

41

42

43

44

45

46

47

48

49

50

51

52

53

54

55

56

57

58

59

60 
Table 4. Factors associated with delayed discharge (sample with completed hospital episode only)

\begin{tabular}{|c|c|c|c|c|c|c|}
\hline Independent variable & $\mathrm{n}$ & $\begin{array}{c}\text { Delay } \\
<3 \text { days } \\
\%\end{array}$ & $\begin{array}{l}\text { Delay } \\
\geq 3 \text { days } \\
\%\end{array}$ & $\begin{array}{c}\text { Test } \\
\text { statistic }\end{array}$ & $\mathrm{df}$ & p-value \\
\hline \multicolumn{7}{|l|}{ Gender } \\
\hline Male & 43 & 51.2 & 48.8 & \multirow{2}{*}{$1.9^{\mathrm{a}}$} & \multirow{2}{*}{1} & \multirow{2}{*}{.163} \\
\hline Female & 86 & 64.0 & 36.0 & & & \\
\hline Age & 127 & & & $1564.0^{\mathrm{b}}$ & & .065 \\
\hline \multicolumn{7}{|l|}{ Living situation prior to admission } \\
\hline Home alone no informal care & 28 & 60.7 & 39.3 & \multirow{4}{*}{$5.0^{\mathrm{a}}$} & \multirow{4}{*}{3} & \multirow{4}{*}{.171} \\
\hline Home with informal care & 73 & 67.1 & 32.9 & & & \\
\hline Care home and ECH & 23 & 43.5 & 56.5 & & & \\
\hline Other & 5 & 40.0 & 60.0 & & & \\
\hline \multicolumn{7}{|l|}{ Physical health status } \\
\hline Poor & 26 & 96.2 & 3.8 & \multirow{2}{*}{$17.5^{\mathrm{a}}$} & \multirow{2}{*}{1} & \multirow{2}{*}{.000} \\
\hline Fair to excellent & 98 & 51.0 & 49.0 & & & \\
\hline Daily functioning (Barthel score) & 130 & & & $1694.0^{\mathrm{b}}$ & & .102 \\
\hline \multicolumn{7}{|l|}{ Cognitive impairment } \\
\hline Low & 95 & 68.4 & 31.6 & \multirow{3}{*}{$10.7^{\mathrm{a}}$} & \multirow{3}{*}{2} & \multirow{3}{*}{.005} \\
\hline Moderate & 14 & 42.9 & 57.1 & & & \\
\hline High & 21 & 33.3 & 66.7 & & & \\
\hline \multicolumn{7}{|l|}{ Behaviour problems } \\
\hline No/low challenging behaviour & 18 & 66.7 & 33.3 & \multirow{2}{*}{$0.4^{\mathrm{a}}$} & \multirow{2}{*}{1} & \multirow{2}{*}{.534} \\
\hline Moderate/high challenging behaviour & 112 & 58.9 & 41.1 & & & \\
\hline \multicolumn{7}{|l|}{ Mental health support pre-admission } \\
\hline No formal mental health support & 28 & 53.6 & 46.4 & \multirow{2}{*}{$.7^{\mathrm{a}}$} & \multirow{2}{*}{1} & \multirow{2}{*}{.399} \\
\hline Formal mental health support & 101 & 62.4 & 37.6 & & & \\
\hline \multicolumn{7}{|l|}{ Social care support pre-admission } \\
\hline No formal social care support & 74 & 68.9 & 31.1 & \multirow{2}{*}{$6.6^{\mathrm{a}}$} & \multirow{2}{*}{1} & \multirow{2}{*}{.010} \\
\hline Formal social care support & 54 & 46.3 & 53.7 & & & \\
\hline Reason for hospital admission & & & & & & \\
\hline $\begin{array}{l}\text { Risk of self-neglect / accidental self- } \\
\text { harm / abuse or exploitation, carer } \\
\text { stress }\end{array}$ & 32 & 56.3 & 43.8 & & & \\
\hline $\begin{array}{l}\text { Challenging behaviour, risk of } \\
\text { deliberate self- harm, other care } \\
\text { breakdown }\end{array}$ & 65 & 66.2 & 33.8 & $2.9^{\mathrm{a}}$ & 2 & .240 \\
\hline Assessment, review or treatment & 29 & 48.3 & 51.7 & & & \\
\hline Hospital site & & & & & & \\
\hline Site X & 52 & 75.0 & 25.0 & & & \\
\hline Site Y & 38 & 73.7 & 26.3 & $25.4^{\mathrm{a}}$ & 2 & .000 \\
\hline Site $\mathrm{Z}$ & 40 & 27.5 & 72.5 & & & \\
\hline
\end{tabular}


Table 5. Factors associated with the likelihood of returning home (sample admitted from home with completed hospital episodes only)

\begin{tabular}{|c|c|c|c|c|c|c|}
\hline Independent variable & $\mathrm{n}$ & $\begin{array}{l}\text { Discharged } \\
\text { home } \\
\%\end{array}$ & $\begin{array}{l}\text { Not } \\
\text { discharged } \\
\text { home } \\
\%\end{array}$ & $\begin{array}{c}\text { Test } \\
\text { statistic }\end{array}$ & df & p-value \\
\hline \multicolumn{7}{|l|}{ Gender } \\
\hline Male & 33 & 81.8 & 18.2 & \multirow{2}{*}{$.04^{\mathrm{a}}$} & \multirow{2}{*}{1} & \multirow{2}{*}{.851} \\
\hline Female & 66 & 83.3 & 16.7 & & & \\
\hline Age & 97 & & & $374.0^{\mathrm{b}}$ & & .008 \\
\hline \multicolumn{7}{|l|}{ Living situation prior to admission } \\
\hline Home alone no informal care & 29 & 82.8 & 17.2 & \multirow{2}{*}{$.0^{\mathrm{a}}$} & \multirow{2}{*}{1} & \multirow{2}{*}{.991} \\
\hline Home with informal care & 70 & 82.9 & 17.1 & & & \\
\hline \multicolumn{7}{|l|}{ Physical health status } \\
\hline Poor & 21 & 85.7 & 14.3 & \multirow{2}{*}{$.05^{\mathrm{a}}$} & \multirow{2}{*}{1} & \multirow{2}{*}{.830} \\
\hline Fair to excellent & 74 & 83.3 & 16.2 & & & \\
\hline Daily functioning (Barthel score) & 99 & & & $339.0^{\mathrm{b}}$ & & .000 \\
\hline \multicolumn{7}{|l|}{ Cognitive impairment } \\
\hline Low & 80 & 91.3 & 8.8 & \multirow{3}{*}{$21.7^{\mathrm{a}}$} & \multirow{3}{*}{2} & \multirow{3}{*}{.000} \\
\hline Moderate & 8 & 37.5 & 62.5 & & & \\
\hline High & 11 & 54.5 & 45.5 & & & \\
\hline \multicolumn{7}{|l|}{ Behaviour problems } \\
\hline No/low challenging behaviour & 16 & 100.0 & 0.0 & \multirow[b]{2}{*}{$4.0^{\mathrm{a}}$} & \multirow[b]{2}{*}{1} & \multirow[b]{2}{*}{.047} \\
\hline $\begin{array}{l}\text { Moderate/high challenging } \\
\text { behaviour }\end{array}$ & 83 & 79.5 & 20.5 & & & \\
\hline \multicolumn{7}{|l|}{ Mental health support pre-admission } \\
\hline No formal mental health support & 25 & 84.0 & 16.0 & \multirow{2}{*}{$.04^{\mathrm{a}}$} & \multirow{2}{*}{1} & \multirow{2}{*}{.837} \\
\hline Formal mental health support & 73 & 82.2 & 17.8 & & & \\
\hline \multicolumn{7}{|l|}{ Social care support pre-admission } \\
\hline No formal social care support & 67 & 88.1 & 11.9 & \multirow{2}{*}{$4.7^{\mathrm{a}}$} & \multirow{2}{*}{1} & \multirow{2}{*}{.031} \\
\hline Formal social care support & 30 & 70.0 & 30.0 & & & \\
\hline \multicolumn{7}{|l|}{ Reason for hospital admission } \\
\hline $\begin{array}{l}\text { Risk of self-neglect / accidental self- } \\
\text { harm / abuse or exploitation, carer } \\
\text { stress }\end{array}$ & 30 & 70.0 & 30.0 & & & \\
\hline Challenging behaviour, risk of & & & & $6.0^{\mathrm{a}}$ & 2 & .050 \\
\hline $\begin{array}{l}\text { deliberate self- harm, other care } \\
\text { breakdown }\end{array}$ & 45 & 91.1 & 8.9 & & & \\
\hline Assessment, review or treatment & 22 & 86.4 & 13.6 & & & \\
\hline Hospital site & & & & & & \\
\hline Site X & 43 & 90.7 & 9.3 & & & \\
\hline Site Y & 22 & 72.7 & 27.3 & $3.7^{\mathrm{a}}$ & 2 & .155 \\
\hline Site Z & 34 & 79.4 & 20.6 & & & \\
\hline
\end{tabular}

${ }^{\mathrm{a} C h i-s q u a r e ;}{ }^{\mathrm{b}}$ Mann-Whitney U test 